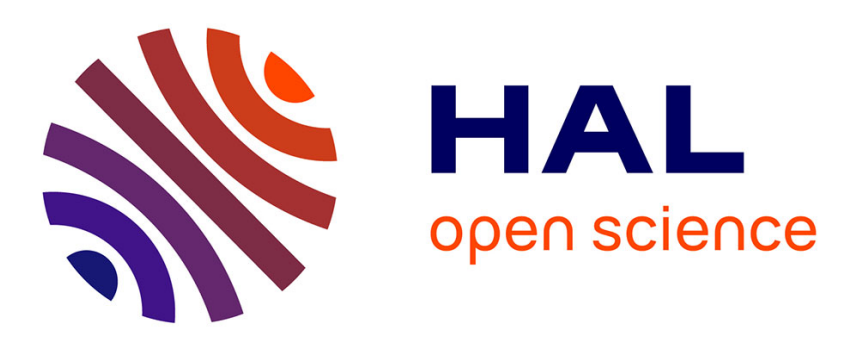

\title{
Identifying the impact of climate and anthropic pressures on karst aquifers using wavelet analysis
}

Jean-Baptiste Charlier, Bernard Ladouche, Jean-Christophe Maréchal

\section{To cite this version:}

Jean-Baptiste Charlier, Bernard Ladouche, Jean-Christophe Maréchal. Identifying the impact of climate and anthropic pressures on karst aquifers using wavelet analysis. Journal of Hydrology, 2015, 523, pp.610-623. 10.1016/j.jhydrol.2015.02.003 . hal-01119955

\section{HAL Id: hal-01119955 https://hal-brgm.archives-ouvertes.fr/hal-01119955}

Submitted on 24 Feb 2015

HAL is a multi-disciplinary open access archive for the deposit and dissemination of scientific research documents, whether they are published or not. The documents may come from teaching and research institutions in France or abroad, or from public or private research centers.
L'archive ouverte pluridisciplinaire HAL, est destinée au dépôt et à la diffusion de documents scientifiques de niveau recherche, publiés ou non, émanant des établissements d'enseignement et de recherche français ou étrangers, des laboratoires publics ou privés. 


\section{Identifying the impact of climate and anthropic pressures}

\section{2 on karst aquifers using wavelet analysis}

4

5 Jean-Baptiste Charlier*, Bernard Ladouche and Jean-Christophe Maréchal

6 BRGM, 1039 rue de Pinville, F-34000 Montpellier, France.

7

8 * Corresponding author: E-mail: j.charlier@brgm.fr; Tel: +33 (0)4 6715 79 77; Fax: +33 (0)4 9967645851.

10

11

12

13

14

\section{Abstract}

This paper assesses the implications of climate and anthropic pressures on short to long-

17 term changes in water resources in a Mediterranean karst using wavelet analysis. This

18 approach was tested on 38-year (1974-2011) hydrogeological time series recorded at the Lez

19 spring (South France), which is exploited for water supply. Firstly, we investigated inter-

20 relationships in the frequency domain by cross-correlation across multiresolution levels. Our

21 results showed that rainfall and spring discharge are highly correlated in the high frequency 
22 domain which reflects the hydrogeological response during flood events of typical highly

23 karstified systems. Pumping and groundwater level are correlated in a lower frequency

24 domain, illustrating seasonal to multi-year relationships. Secondly, continuous wavelet

25 transform was applied to characterize the temporal variability of the inter-relationships

26 involved. On the contrary to examples of "non-managed" karst aquifers in the literature, our

27 results showed that the 10-year rainfall component was attenuate in the discharge signal. We

28 assume that the reason is that the storage variations are strongly affected by pumping. This

29 interesting result shows that possible long-term impacts of rainfall variability due to climate

30 change may be masked by a high pumping rate. We showed also that despite an increase of

31 the pumping rate from the 1980s, the stress on the groundwater resource does not increase

32 from year to year. The present pumping strategy does not affect the drawdown in the long

33 term, avoiding an over-exploitation of the aquifer. Finally, this study highlights the

34 effectiveness of wavelet analysis in characterizing the response variability of karst systems

35 where the hydrogeological regime is modified by pumping.

39 Karst; Wavelet transform; Multiresolution analysis; Hydrogeological processes; Climate and

40 anthropic pressures; Signal processing 


\section{$41 \quad 1$ Introduction}

Groundwater is a major global water supply resource and is currently affected by two

43 main stressors: climate and anthropic pressures. This is essentially true for aquifers pumped

44 for water supplies in Mediterranean areas due to increased abstraction to meet the needs of the

45 growing population in regions where the aquifer is irregularly recharged from one year to the

46 next. Evaluating the impacts of climate and anthropic pressure on water resources in such

47 regions is a major challenge, as most large aquifers are located in carbonate rocks subject to

48 karstification. The hydrogeological response of karst systems is highly non-linear due to

49 spatial and dynamic heterogeneities linked to fact that the void structure leads to the

50 formation of preferential drainage axes (for reviews see Bakalowicz, 2005; Goldscheider et

51 al., 2007). Some of karst aquifers are an important water source for major cities, particularly

52 in Mediterranean regions. In these cases, the aquifer may be referred to as "actively managed"

53 if the pumping rate is higher than the low water stage discharge rate of the system under

54 natural conditions in summer. Then, groundwater storage is highly mobilized before the rainy

55 autumn period that contributes most of the annual recharge each year. In this paper, we

56 investigate climatic and anthropic impacts on the groundwater resource in a Mediterranean

57 karst system under active water management. We ask whether pumping modified the

58 hydrogeological response.

59 Wavelet analysis has become a powerful technique to study geophysical processes or

60 signals (Kumar and Foufoula-Georgiou, 1997; Torrence and Compo, 1998). Decomposing a

61 time series into time-scale space, this method localizes power variations within a time series.

62 It is ideal for analysing non-stationary signals and identifying short- to large-scale periodic

63 phenomena. In the field of hydrology, Continuous Wavelet Transforms (CWT) have recently 
64 been used to study the effect of climatic phenomena on the stream flow regime (Labat et al., 65 2005; Massei et al., 2007; Labat, 2010; Fu et al., 2012), or to study runoff processes 66 (Lafrenière and Sharp, 2003; Schaefli et al., 2007). CWT has been widely used to study the 67 hydrogeological behaviour of karst systems. Comparing three springs, Labat et al. (2000; 68 2002) demonstrated the potential of wavelet analysis in identifying karst properties in relation 69 to the degree of karstification. Structural heterogeneity also determines similar filtering 70 properties on a small basin scale (Chinarro et al., 2011) and on a large scale (Hao et al., 71 2012): i) short time-scale signals are generally less filtered showing the transmissive role of 72 the conduit network, ii) and high-energy large timescale signals can penetrate through the 73 aquifer, illustrating the buffered role of the storage zone. In a Mediterranean context, this 74 allows us to visualize annual and multi-annual scale components in relation to North Atlantic 75 Oscillation (Andreo et al., 2006). The hydrogeological response has also been studied from a 76 physico-chemical time series: to investigate transport properties and turbidity dynamics 77 (Massei et al., 2006), to highlight temperature-runoff relationships during snowmelt 78 (Mathevet et al., 2004), or to study groundwater variations in relation to the geological 79 context (Slimani et al., 2009). Surface-groundwater interactions were also studied using CWT 80 to improve understanding of river flow components in karst environments (Salerno and 81 Tartari, 2009). But, there is a lack of knowledge regarding the identification of the respective 82 role of climatic and anthropic pressures on the resource of karst aquifers. Generally, CWT provides a good representation of energy distribution in time-scale 84 space in all these works, highlighting the non-stationary nature and multi-scale behaviour of 85 karst systems. However, to overcome limitations arising from intrinsic redundancy of the 86 CWT representation, Labat et al. (2000; 2001) applied an orthonormal wavelet representation, 
87 conserving the signal information, as a complementary approach. This multiresolution

88 analysis (discrete wavelet transform DWT) can be used to decompose a signal into successive

89 resolution levels. It allows the energy distribution across levels to be characterized and the

90 slow and fast components in a spring discharge time series to be distinguished. This

91 complementary DWT technique allows easier and more efficient interpretation of the energy

92 distribution across decomposition scales, assisting the study of the time-frequency space of

93 time series. It can thus greatly improve hydrogeological understanding of karst systems, but is

94 rarely found in the literature. From these latest studies showing the significant potential of

95 combined CWT and DWT, we expect that both approaches will be adapted to characterize on

96 groundwater resources the response to the cumulative effect of climatic and anthropic

97 pressures.

98 To assess the impacts of climatic and anthropic pressure on groundwater resources in a

99 karst system under active water management, this study aims to distinguish between the role

100 of rainfall and pumping on the karst response using wavelet analysis. As a first step, a

101 multiresolution analysis was performed in order to characterize the energy distribution across

102 scales. To identify the frequency domain where rainfall and pumping may influence the karst

103 system, we also present a cross-correlation across multi-resolution levels. As a second step,

104 continuous wavelet analysis was applied to track changes in phenomena over time, providing

105 information on the temporal variability of the karst response to climatic and anthropic

106 stressors. We applied these techniques on rainfall, pumping, discharge and piezometric time

107 series over a 38-year period (1974-2011) in the Lez aquifer in the South of France. 


\section{Site and measurements}

109

110

111

112 France, in the western section of the Mediterranean zone. The Lez karst system is part of the

113 North Monpelliérains karst hydrogeological unit bounded to the west by the Hérault River

114 and to the north and east by the Vidourle River (Figure 1). The Lez karst aquifer is located in

115 Upper Jurassic formations between $650 \mathrm{~m}$ and $800 \mathrm{~m}$ thick, located on both sides of the

116 Matelles fault. The aquifer is unconfined to the west of the fault, while the section located to

117 the east may be partially captive. In the zone lying under a Tertiary overburden, the aquifer is

118 found in the Upper Jurassic and the Lower Cretaceous. A more detailed description of the 119 study area can be found in Ladouche et al. (2014).

120 The Lez spring is the main outlet of the karst system (Figure 1). The spring outlet has

121 been explored by cave-divers. They discovered a huge saturated sub-horizontal karst conduit

122 developing more than $400 \mathrm{~m}$ inland (Figure 2), with a diameter ranging between 5 and $10 \mathrm{~m}$.

123 The exploration ended at $113 \mathrm{~m}$ deep below the spring outlet (-48 m ASL) in a zone where the

124 conduit become wider. The hydrogeological basin is estimated to cover an area of $380 \mathrm{~km}^{2}$

125 (Thiery et al., 1983). Different recharge zones can be distinguished, depending on the nature

126 of the geological overburden. Recharge of the aquifer takes place predominantly in Jurassic

127 limestone, occupying an area of 80 to $100 \mathrm{~km}^{2}$ (Figure 1). Within the Cretaceous overburden

$128\left(120 \mathrm{~km}^{2}\right)$, losses occur locally along temporary watercourses and feed the aquifer locally 129 during flood events. The Tertiary formations occupy an area of about $160 \mathrm{~km}^{2}$. In general 
130 these are considered as impermeable or almost impermeable and do not contribute to

131 recharging the Lez karst aquifer.

132 The drinking water supply of the Montpellier agglomeration (with about 340000

133 inhabitants) comes from the Lez karst spring since the 19th century (1854). Before 1968, this

134 resource was used by gravity extraction, varying between $25.10^{-3}$ and $0.6 \mathrm{~m}^{3} / \mathrm{s}$ (Paloc, 1979).

135 From 1968 to today, the Lez karst spring is pumped according an active management strategy,

136 the pumping flow rate during summer periods is greater than the spring's low-water discharge

137 so as to mobilize the aquifer's stored reserves (Avias, 1995). From 1968 to 1982, water was

138 abstracted by pumping in the Lez Spring basin (Figure 2a) at a rate of the order of $0.8 \mathrm{~m}^{3} / \mathrm{s}$.

139 From 1983 onwards, deep boreholes located in the main karst conduit located upstream from

140 the spring (Figure 2) have allowed pumping at a rate of up to $1.7 \mathrm{~m}^{3} / \mathrm{s}$ (Avias, 1995). The

141 pumping flow rates during low groundwater levels $\left(1.2\right.$ to $\left.1.7 \mathrm{~m}^{3} / \mathrm{s}\right)$ currently exceed the

142 pumping flow rates during high groundwater levels $\left(0.9 \mathrm{~m}^{3} / \mathrm{s}\right)$. The minimum groundwater

143 level is fixed at $35 \mathrm{~m}$ a.s.1 in the main conduit. The maximum drawdown permitted from

144 pumping is thus $30 \mathrm{~m}$ below the overflow threshold of the spring ( $65 \mathrm{~m}$ a.s.l., Figure $2 \mathrm{~b}$ ). The

145 lowest water level (i.e. 35 m a.s.1.) was reached during the 1995 hydrological cycle. For

146 environmental reasons, a reserve flow rate of $0.160 \mathrm{~m}^{3} / \mathrm{s}$ is restored for the Lez River

147 downstream of the spring when it is not overflowing.

\section{$148 \quad 2.1 .2$ Hydrogeological background}

149 The conceptual scheme of the Lez aquifer, built by Salado and Marjolet (1975) and 150 completed recently by Bicalho et al. (2012), shows that the water from the Lez spring 151 comprises a mixture of water from three main units in the aquifer: i) water from the aquifer in

152 the Upper Jurassic limestone and the Lower Cretaceous; ii) surface water (losses) after 
153 interacting with the Cretaceous formations; and iii) water from deep circulation in the

154 underlying Middle Jurassic, having long residence time.

155 The hydrogeological functioning of the Lez karst system has been characterized using

156 various rainfall-discharge modelling approaches accounting for pumping (Guilbot, 1975;

157 Thiery and Bérard, 1984; Fleury et al., 2009). These works showed that pumping during low

158 water periods draw out reserves coming from less transmissive zones in addition to the well-

159 drained reserves. An assessment of this pumping influence area around the network of karst

160 conduits give values of about $60 \mathrm{~km}^{2}$ (Ladouche et al., 2014), representing only $15 \%$ of the

161 Lez spring's catchment.

162 Recent semi-distributed modelling approaches have given a first assessment of the

163 contributions of the main karst units. Simulating the groundwater level in the main drain at

164 the karst outlet using a semi-distributed lumped model, Ladouche et al. (2014) showed that

165 the eastern part of the Matelles fault is contributing 2-fold higher than the western part. This

166 result is coherent with previous works of Kong A Siou (2011) applying neuron models in a

167 semi-distributed approach.

\section{$168 \quad 2.2$ Hydrogeological data}

\section{2.2.1 Measured data}

170 Hydrogeological measurements have been carried out since 01 June 1974 to 31

171 December 2011. Figure 1 shows the locations of the monitoring sites from which data are

172 used in this study.

173 Daily precipitation intensity was measured in the three weather stations at St-Martin-de-

174 Londres, Valflaunes and Montpellier-Fréjorgues (Méteo France, 2012). 
176 intervals from 1974 to 2000, except during the 1991 to 1996 period when measurements were

177 recorded at weekly intervals. Since 2000, $Q p$ has been recorded at hourly intervals.

178 Until 1982, the piezometric level $(h)$ was measured in the Lez spring basin at daily

179 intervals. Since 1983, $h$ has been measured directly in the main conduit in a borehole located

180 upstream from the spring (Figure 2). Groundwater levels have been recorded on a daily basis

181 from 1974 to 2000, except during the 1991-1996 period when measurements were recorded at

182 weekly intervals. Since 2000, $h$ has been recorded at hourly intervals. Since $h$ expresses

183 groundwater level relative to mean sea level, we also define a drawdown value $s$ which

184 expresses the groundwater level measured from the maximum head $h$ max $(s(t)=h$ max $-h(t))$.

185 The value $s$ was used instead of $h$ in wavelet analysis in order to correlate an increased

186 pumping rate with increased groundwater fluctuation (as the pumping rate increase is 187 inversely correlated with the piezometric level).

188 Measured discharge at the Lez spring is denoted residual discharge $(Q r)$, because the 189 gauging station (Banque Hydro, 2010) is located $300 \mathrm{~m}$ downstream the outlet were pumping

190 are carried out (Figure 2). Qr was measured between 1987 and 2007 at daily intervals. Data

191 were corrected from the restored discharge $\left(0.160 \mathrm{~m}^{3} / \mathrm{s}\right)$ to the Lez River when the spring was 192 dry. Before 1987, Qr was estimated from water level measurements in the basin. Minimum $193 Q r$ value is zero.

\section{$194 \quad$ 2.2.2 Calculated data}

195 Precipitation data $(P)$ used in this study is the rainfall time series calculated by 196 Ladouche et al. (2014) to optimize the contribution of three rain gauges in their developed

197 transfer model used to simulate the spring discharge. The method - given by Pinault and 
198 Allier (2007) - requires to compute the weighting factor of each rain gauge in order to

199 maximize the cross-correlation (see Section 3.1 for equations) between $P$ and residual 200 discharge ( $Q r)$ measured between 1987 and 2007. The linear combination obtained for $P$ is:

$$
P=0.33 P 1+0.54 P 2+0.13 P 3
$$

202 where $P 1$ is the precipitation at St-Martin-de-Londres, $P 2$ is the precipitation at Valflaunes, 203 and $P 3$ is the precipitation at Montpellier-Fréjorgues (Figure 1).

204 During high water period - when overflows are observed at the spring (residual 205 discharge $Q r>0)$ - pumping is inferior to the natural discharge $(Q n)$. $Q r$ is interpreted as the 206 difference between $Q n$ and $Q p: Q r=Q n$ - $Q p$. According to Ladouche et al. (2014), pumping 207 mobilizes water stored only in the large conduit (where pumps are localised) during this 208 period, because no drawdown related to pumping was observed on piezometric $h(t)$ time 209 series, as well as in the more distant connected piezometer Claret well (see Fig. 1 for 210 location). Consequently, during high water period, we assume that the storage flow mobilized 211 by pumping $(Q s)$ is negligible (almost equal to 0 ).

212 During low water period - when pumping has dried the spring $(Q r=0)$ - pumping is 213 superior to $Q n$, and $Q p$ is interpreted as the sum of $Q n$ and the $Q s$ (Ladouche et al., 2014): $Q p$ $214=Q n+Q s$. Pumping thus mobilizes water reserves in the karst system that are inaccessible or 215 almost inaccessible in natural conditions. This phenomenon is reflected in a decrease of the 216 piezometric level in the karst conduit (groundwater level $<65 \mathrm{~m}$ a.s.l., Figure $2 \mathrm{~b}$ ).

217 The storage flow mobilized by pumping $Q s$ is calculated by equation 2 (Ladouche et al., 218 2014):

$$
\begin{aligned}
& \text { if } Q p \geq Q n \text { then } Q s=Q p-Q n \text { and } Q r=0 \\
& \text { if } Q p<Q n \text { then } Q s \approx 0 \text { and } Q r=Q n-Q p
\end{aligned}
$$


This last equation requires to assess $Q n$ which is unknown during low water level

221 periods, as the Lez spring has been used since 1854 to supply drinking water (Paloc, 1979).

222 During high water level periods (Figure 2a), $Q n$ is higher than the pumping rate $(Q p)$, and can

223 be calculated as follows: $Q n=Q r+Q p$. During periods of low water levels (Figure $2 \mathrm{~b}$ ), $Q n$

224 cannot be estimated from measurements. Recently, Ladouche et al (2014) have simulated the

225 Qn time series using a transfer model combining a fast and a slow impulse response. Impulse

226 responses were calculated by inverse modelling during high flow periods when $Q n=Q r+$

$227 Q p$. The whole $Q n$ time series was then simulated from 1974 to 2011 using the Tempo

228 software (Pinault, 2001 ; Pinault et al., 2001a, b).

All hydrogeological time series for rainfall $(P)$, Lez discharge ( $Q r$ and $Q n)$, pumping

230 discharge $(Q p)$ and piezometric levels $(h)$ for the period from 01 June 1974 to 31 December

2312011 were synchronized at a time interval of 1 day.

232 2.2.3 Hydrogeological variables used to assess the karst response to stressors

This section presents the hydrogeological variables used as input and output to characterize the response of the karst system to climatic and anthropic stressors. Table 1

236 provides an overview of the set of variables, also showing the framework for interpreting their

237 possible inter-relationships. The purpose of this guide is to help to interpret the results of the 238 wavelet analysis used in this article.

The input variables representing specifically climatic pressure and anthropic pressures 240 are precipitation $P$ and pumping $Q p$, respectively. As the $Q s$ variable is defined from $Q n$ and

$241 Q p$, (Eq. 2), and $Q n$ is highly correlated to $P, Q s$ integrates these both climatic and anthropic

242 pressures. With regard to the output variables, the residual discharge $Q r$ qualifies the karst 
243 response to the rainfall during high flows periods. The water level $(h)$ and especially the 244 drawdown $(s)$ qualify the karst stored changes due to inputs solicitation (precipitation and 245 pumping).

246 Two ambiguous input-output relationships for the defined set of variables were 247 identified. The $P$ - $h$ relationship is disrupted by the impact of pumping on the water level $h$ 248 (major drawdown during the summer). Similarly, $Q p$ cannot be used to study properly the 249 impact of pumping on $Q r$, since the latest is controlled by both $P$ and $Q p$ variables. 250 Consequently, these two relationships were removed from the presented analysis. We will 251 focus our analysis on the $P$ - $Q r$ relationship to assess the impact of the climate pressure on the 252 karst functioning. The $Q p-s$ relationship is used to assess the anthropic impact on the 253 reserves. Finally, $Q s-Q r$ and $Q s-s$ relationships are used to assess the vulnerability of the 254 resource to both climatic and anthropic pressures.

\section{Wavelet analysis}

The functions used are briefly presented on the basis of definitions put forward by 257 several authors for wavelet analysis in geosciences (Kumar and Foufoula-Georgiou, 1997; 258 Torrence and Compo, 1998; Labat et al., 2000; Bayazit and Aksoy, 2001; Grinsted et al., 259 2004; Jevrejeva et al., 2003; Maraun and Kurths, 2004). Wavelet transform can be used to 260 decompose a time series over a time-scale space, thus providing a visualization of power 261 distribution along time and frequency. It is suitable for analysis of non-stationary processes 262 that contain multi-scale features, detection of singularities, or transient phenomena (see the 263 review of Kumar and Foufoula-Georgiou, 1997). Thus, wavelet analysis gives a time-scale 264 representation of the processes and of their relationships. 


\subsection{Continuous wavelet transforms}

The wavelet transform can be seen as a bandpass filter of uniform shape and varying

267 location and width (Torrence and Compo, 1998). The continuous wavelet transform (CWT)

$268 W_{x}(\tau, a)$ of a time series $x(t)$ is given as follows:

269 (Eq. 3)

$$
W_{x}(\tau, a)=\int_{-\infty}^{+\infty} x(t) \Psi_{\tau, a}^{*}(t) d t
$$

270

$$
\text { (Eq. 4) } \quad \text { where } \quad \Psi_{\tau, a}=\frac{1}{\sqrt{a}} \Psi\left(\frac{t-\tau}{a}\right)
$$

271 represents a group of wavelet functions, $\Psi_{\tau, a}$, based on a mother wavelet $\Psi$ which can be 272 scaled and translated, modifying the scale parameter $a$ and the translation parameter $\tau$ 273 respectively. $\Psi_{\tau, a}^{*}$ corresponds to the complex conjugate of $\Psi_{\tau, a}$. Wavelet functions have multi274 scale properties, dilating or contracting $a(a>1 ; a<1)$. When $a$ increases, the wavelet covers a 275 higher signal window. It allows the large-scale behaviour of $x$ to be extracted. Conversely, 276 when $a$ decreases, the analysed signal window decreases, allowing local variations of $x$ to be 277 studied. Wavelet transform is thus characterized on the space scale by a window decreasing in 278 width when we focus on local scale structures (high frequency), and widening when we focus 279 on large scale structures (low frequency).

As in the Fourier analysis, a wavelet power spectrum (WPS) (also called a scalogram)

$281 P_{x}(\tau, a)$ can be defined as the wavelet transform of $W_{x}(\tau, a)$ :

282 (Eq. 5)

$$
P_{x}(\tau, a)=\left(W_{x}(\tau, a) W_{x}^{*}(\tau, a)\right)=\left|W_{x}(\tau, a)\right|^{2}
$$

The choice of the appropriate analysis wavelet depends on the nature of the signal and 284 on the type of information to be extracted from the time series (De Moortel et al., 2004). In 285 this paper, we use the Morlet wavelet, as it is fairly well localized in both time and frequency 286 space (Torrence and Compo, 1998). Other wavelet basis functions, such as Paul and Mexican 
287 hat (DOG), were also tested in order to obtain better time localization, but gave the fairest

288 results in both cases. Statistical significance level was estimated against a red noise model 289 (Torrence and Compo, 1998, Grinsted et al., 2004). As CWTs are applied to time series of

290 finite length, edge effects may appear on the scalogram, leading to the definition of a cone of

291 influence (COI) as the region where such effects are relevant (Torrence and compo, 1998).

292 The COI is marked as a shadow in the scalogram.

293 The covariance of two time series $x$ and $y$ is estimated using a cross wavelet spectrum 294 (XWT) (also called a cross scalogram) $W_{x y}(\tau, a)$, which is the convolution of the scalogram of 295 both signals:

$296 \quad W_{x y}(\tau, a)=\left(W_{x}(\tau, a) W_{y}^{*}(\tau, a)\right)$

297 XWT reveals an area with a high common power value, but Maraun and Kurths (2004) 298 reported that it appears unsuitable for significance testing of the interrelation between two 299 series. These authors recommend the use of wavelet coherence (WTC) which is a measure of 300 the intensity of covariance of the two series in the time-scale space. Beginning with the 301 approach of Torrence and Webster (1999), the WTC of two time series $x$ and $y$ is defined as:

302 (Eq. 7)

$$
C_{x y}^{2}(\tau, a)=\frac{\left|S\left(a^{-1} W_{x y}(\tau, a)\right)\right|^{2}}{S\left(a^{-1}\left|W_{x}(\tau, a)\right|^{2}\right) \cdot S\left(a^{-1}\left|W_{y}(\tau, a)\right|^{2}\right)}
$$

303 where $S$ is a smoothing operator in both time and scale (see Torrence and Webster (1999) and 304 Jevrejeva et al. (2003) for detailed mathematical expressions). The 5\% significance level of 305 WTC against red AR1 noise is estimated using Monte Carlo methods (Grinsted et al., 2004). Neighbouring scales and times contain redundance information and are correlated 307 (Maraun and Kurths, 2004), since the wavelet is translated continuously. However, some 
approaches exist to limit this redundancy, as is the case with Discrete wavelet analysis (Labat et al., 2000; Bayazit and Aksoy, 2001) based on a wavelet with an orthogonal form.

\subsection{Discrete wavelet transform and multiresolution analysis}

312 transform (DWT) can be used to discretize the scale and location parameters $j$ and $k$, 313 respectively. The discrete form of the wavelet transform of a time series $x(t)$ is given 314 according to Eq. 8:

315 (Eq. 8)

$$
W_{x}\left(\tau_{0}, a_{0}\right)=\sum_{-\infty}^{+\infty} x(t) \Psi_{\tau_{0}, a_{0}}^{*}(t) d t
$$

316 (Eq. 9) where $\Psi_{\tau_{0}, a_{0}}=\frac{1}{\sqrt{a_{0}^{j}}} \Psi\left(\frac{t-k a_{0}^{j} \tau_{0}}{a_{0}^{j}}\right)$

317 with $a_{0}^{j}$ being the scale parameter, $\tau_{0}$ the translation parameter, $k$ and $j$ integers. $\Psi_{\tau_{0}, a_{0}}^{*}$ 318 corresponds to the complex conjugate of $\Psi_{\tau_{0}, a_{0}}$.

319 Multiresolution analysis (MRA) is able to study of signals represented at different 320 resolutions. It can be used to decompose a signal into a progression of successive 321 approximations and details in increasing order of resolution. Choosing particular values of $a_{0}$ 322 and $\tau_{0}$, in Eq. 8, namely $a_{0}=2$, and $\tau_{0}=1$, corresponds to the dyadic case used in MRA. The 323 aim is to reduce/increase the resolution by a factor of 2 between two scales. Therefore, the 324 approximation of a signal $x(t)$ at a resolution $j$, denoted by $A_{x}^{j}$, and the detail of the same 325 function at a resolution $j$, denoted by $D_{x}^{j}$, are defined by:

$326 \quad$ (Eq. 10) $\quad A_{x}^{j}(t)=\sum_{k=-\infty}^{+\infty} C_{j, k} \Psi_{j, k}(t)$

$327 \quad$ (Eq. 11) $\quad D_{x}^{j}(t)=\sum_{k=-\infty}^{+\infty} D_{j, k} \Phi_{j, k}(t)$ 
where $\Phi_{j, k}(t)$ is a scaled and translated basis function called the scaling function, which

329 is determined with $\Psi_{j, k}(t)$ when a wavelet is selected. $C_{j, k}$ is the scaling coefficient given the

330 discrete sampled values of $x(t)$ at resolution $j$ and location $k$. It is calculated from $\Phi_{j, k}(t)$ in a

331 similar way for the wavelet coefficient $D_{j, k}$ from $\Psi_{j, k}(t)$ (see Kumar and Foufoula-Georgiou

332 (1997) for detailed mathematical expressions).

The signal $x(t)$ can be reconstructed from the approximation and detail components as:

334 (Eq. 12)

$$
x(t)=A_{x}^{j}(t)+\sum_{j=1}^{J} D_{x}^{j}(t)
$$

335 where $J$ is the highest resolution level considered. Since MRA ensures variance is well

336 captured in a limited number of resolution levels, analysis of energy distribution in the

337 sampling time series across scales give a good idea of the energy distribution across

338 frequencies.

The choice of wavelet may influence the decomposition, particularly in low frequencies

340 (Kumar and Foufoula-Georgiou, 1997). We accordingly tested various wavelet functions

341 (Haar, Battle, Beylkin, Coiflet, Daubechies, Symmlet, Vaidyanathan) in order to assess the

342 dispersion of results. Since the results were similar overall in the high frequency domain and

343 less influenced in the lowest, we opted for the frequently used Daubechies 20 wavelet.

344 In order to quantify the relationship quality between two signals across scales, we used

345 a multiresolution cross-analysis, combining multiresolution with cross-correlation (Labat et

346 al., 2002). Cross-correlation can be used to determine the degree of similarity between two

347 signals or two components (at the same resolution level for instance). The cross-correlation

348 function (CCF) $R_{x y}$ of two time series $x$ and $y$, is calculated as follows:

349 (Eq. 13)

$$
R_{x y}(m)=\frac{C_{x y}(m)}{\sigma_{x} \sigma_{y}}
$$


350 (Eq. 14)

$$
\text { with } \quad C_{x y}(m)= \begin{cases}\frac{1}{n} \sum_{t=1}^{n-m}\left(x_{t}-\bar{x}\right)\left(y_{t+m}-\bar{y}\right) & \text { for } m \geq 0 \\ \frac{1}{n} \sum_{t=1}^{n+m}\left(y_{t}-\bar{y}\right)\left(x_{t+m}-\bar{x}\right) & \text { for } m<0\end{cases}
$$
where $C_{x y}$ is the cross-correlogram, $m$ is the time lag, $n$ is the length, and $\bar{x}$, and $\sigma_{x}$, and

$352 \bar{y}$ and $\sigma_{y}$, are the average and the standard deviation of $x$ and $y$, respectively.

More treatments of the wavelet transform (both continuous and discrete) and wavelet355 based multiresolution (multi-scaling) analysis can be found in Chui (1992), Kumar and 356 Foufoula-Georgiou (1997), and Mallat (2009) to which the reader is referred for more detail. 357 Continuous wavelet analyses (CWT, XWT, and WTC) were carried out using a free Matlab 358 software package (Mathworks, Natick, MA) kindly provided by Grinsted et al. (2004) at 359 http://noc.ac.uk/using-science/crosswavelet-wavelet-coherence. The package includes code 360 originally written by C. Torrence and G. Compo, available at: $361 \mathrm{http}: / /$ paos.colorado.edu/research/wavelets/, and by E. Breitenberger of the University of 362 Alaska, adapted from the freeware SSA-MTM Toolkit: http://www.atmos.ucla.edu/tcd/ssa/. 363 Multiresolution analysis was carried out using a free Matlab software package provided by 364 the WaveLab Development Team and available at http://statweb.stanford.edu/ wavelab/.

\section{Results}

\section{$366 \quad 4.1$ Variability of hydrogeological time series}

This Section aims to describe the main variations over hydrological cycles from daily to

368 annual data, in order to help readers to interpret the results of the wavelet analysis given in the 369 next Sections 4.2 and 4.3. 


\subsubsection{Daily variability}

371

372

373

374

375

376

377 387 increases to high values (around $1.0 \mathrm{~m}^{3} / \mathrm{s}$ ). The first abundant autumn rainfall in September 3882003 led to rapid groundwater recovery to the initial level of $65 \mathrm{~m}$ a.s.l. as observed on the

389 groundwater level time series $(h)$. This phenomenon occurred in less than one day. The spring 390

Figure 3a shows daily hydrogeological time series of the Lez karst system over the last 38 years. Overall, the Mediterranean climate has a high rainfall intensity, for example attaining $177.5 \mathrm{~mm} /$ day in autumn 1976 . The mean pumping discharge is around 1 to 1.1 $\mathrm{m}^{3} / \mathrm{s}$, exceeding the natural baseflow of the Lez spring. To better describe the variability of other hydrogeological data within a given year, Figure $3 b$ zooms in on the 2002-2003 hydrological year. Heavy rainfall occurs in the end of the summer and in autumn with an intensity of up to $140 \mathrm{~mm} /$ day, generating the highest annual peak flow $\left(15.4 \mathrm{~m}^{3} / \mathrm{s}\right.$ for $\left.Q r\right)$ at the Lez spring and a rise in groundwater level $(h)$ from 65 to $69 \mathrm{~m}$ a.s.l.. In the winter and spring seasons, lower rainfall intensities generate lowest hydrodynamic response of the karst system as shown by small flood peaks inferior to $5 \mathrm{~m}^{3} / \mathrm{s}$ and low groundwater variations. During this period of high groundwater level, $Q p$ is near to $1.0 \mathrm{~m}^{3} / \mathrm{s}$ and consistently below $Q n$ : the spring is discharging $(Q r>0)$. At the beginning of the dry season in summer, $Q p$ increases to $1.4 \mathrm{~m}^{3} / \mathrm{s}$ and exceeds $Q n$. The spring consequently dries up ( $Q r$ is zero), and $h$ starts to decrease (water is pumped directly from the conduit). During the low groundwater period in summer, the drawdown reaches $25 \mathrm{~m}$ (i.e. the piezometric level drops to $40 \mathrm{~m}$ a.s.l.). The saturated zone is highly mobilized by pumping and the reserve storage flow $(Q s)$ then starts to discharge again $(Q r>0)$ and another similar hydrological cycle begins. 


\subsubsection{Annual variability}

To identify humid and dry periods and changes in the pumping discharge on an annual time scale, Figure 4 shows the annual hydrogeological time series expressed as deviation from

394 the mean. The highest peaks for precipitation $P$ occur in 1976-78, 1987-88, 1995-97, 2000-01, 395 2002-04 and 2008-09. Although annual discharge peaks (Qr) are clearly related to these

396 humid years, there is no evidence of any relationship with groundwater level $(h)$. Regarding 397 annual pumping $(Q p)$ and karst storage flow mobilized by pumping $(Q s)$, we observed two 398 periods. From 1974 to 1984 both time series are consistently below the mean (except in 197939980 for pumping), unlike the period from 1984 to the present, during which the time series are 400 higher for most of the time. These periods correspond respectively to a high and a low annual 401 mean groundwater level, meaning that the groundwater level is primarily linked to pumping, 402 leading to a rise in $Q s$ as pumping rates increase. These results highlight the changes in water 403 resource management from 1983, when water abstraction from deep boreholes began. This 404 allows a higher pumping rate, less constrained in terms of drawdown. Before 1983, the 405 position of the pump in the basin of the spring did not allow the water level to drop to more 406 than $7 \mathrm{~m}$, as opposed to $30 \mathrm{~m}$ today.

\subsection{Multiresolution analysis}

\subsubsection{Energy distribution across scales}

The main aim of this section is to visualize the distribution of energy across scales (or resolution levels) of the hydrogeological time series. Multiresolution was performed on daily data and the results for the first 10 multiresolution levels are shown in Figure 5. Overall, energy is distributed variably across levels in the hydrogeological time series. Regarding 
413 input signals, precipitation $P$ showed high energy mainly for levels 1 to 4 in the high

414 frequency domain (corresponding to 1 to 8 days). This means that rainfall events on several 415 days explain most of the variance in the overall $P$ signal. The pumping discharge rate $Q p$ 416 showed high energy at all levels. Daily to weekly $Q p$ variations are clearly highlighted as 417 noise in the first levels. For levels 6 to 10, we observed a gradual decrease in energy during 418 the 1980s. This was clearly visible on raw data (see Figure 3a). As with the pumping signal, 419 the karst storage flow $(Q s)$ showed high energy across levels. On the other hand, it shows a 420 gradual energy increase in the 1980s. Regarding the output data for the karst system, the both 421 residual discharge $(Q r)$ and groundwater level $(h)$ showed high energy distribution across 422 scales, but different fluctuations over time. For $Q r$, energy distribution appears to be related to 423 flood events for high frequencies (levels 1 to 4 , corresponding to 1 to 8 days), and to seasonal 424 and annual variations for lowest frequencies (levels 8, corresponding to 128 days). Energy 425 variations for the groundwater level are in the same range regardless of the resolution level, 426 meaning that scale has no apparent effect on groundwater variance. For all levels, $h$ energy 427 fluctuations over time in the 1980s are consistent with the previously observed gradual 428 increase and decrease of $Q s$ and $Q p$ respectively.

429 In order to quantify the energy by multiresolution levels, the standard deviation (s.d.) 430 was calculated by levels for each standardized time series (Figure 6). Overall, as previously 431 described, $P$ energy distribution across levels is totally different from other hydrogeological 432 data. Figure 6 shows that s.d. of $P$ decreases from 0.53 to about 0 for low to high 433 multiresolution levels, meaning that the higher the frequency domain, the higher the energy. 434 For other time series, we observe a similar main s.d. peak at level 8 (128 days), meaning that 435 the highest energy is observed for medium levels, corresponding to intra-annual (seasonal) 
periods. A second, lower s.d. peak is observed at levels 10 (512) and 12 (5.6 years) showing

437 that high energy is also observed for annual and multi-year periodicities. Nevertheless, the

438 s.d. of these time series is not negligible in the first levels, meaning that unlike precipitation,

439 energy is still important across scales.

440

442

443

444

445

446

447

448

449

450

454

455

456

458

\subsubsection{Multiresolution cross-correlation}

To identify the frequency domain where input signals may influence karst system behaviour, in this section we present a cross-correlation function (CCF) across multiresolution levels (Figure 7). As shown in Table 1, the input signals used are $P, Q p$, and $Q s$ and the output signals used are $Q r$, and $s$ (instead of $h$ ). For each plot, two types of CCF were carried out. In a first case, as proposed by Labat et al. (2002), a CCF was carried out between two signals at the same multiresolution level $j$ (black circles). In a second case, we chose to carry out a CCF between an overall input signal (i.e. a non-decomposed time series) and an isolated output signal at a given multiresolution level $j$ (green stars). The maximum cross-correlation values $R_{\max }$ are shown in Figure 7 as a function of the multiresolution levels of the output signal expressed in days (at level $j$, the resolution corresponds to $2^{j-1}$ days).

In the first case (CCF between two signals at the same multiresolution level), the higher the multiresolution level, the higher the value of $R_{\max }$ up to 1 . In contrast, we observed a $R_{\max }$ peak in the second case (CCF using an overall input signal). This difference shows that the output signal at a given multiresolution level is strongly influenced by the energy at lower resolution levels of the input signal. We can thus hypothesize that in the first case the CCF was controlled mainly by the resolution level of the decomposed times series. The $R_{\max }$ values of 1 (indicating that the output signal is exactly the same as the input signal) for the highest multiresolution levels are compatible with this hypothesis. Consequently, only the CCFs 
between an overall input signal and an isolated output signal at a given multiresolution level

460 (green stars) were considered for the analysis of multiresolution cross-correlation.

463 The highest correlation (around 0.30) occurs for levels 2 and 3, corresponding to 2 and 4-day

464 resolution periods. This means that time series mainly co-vary in the high frequency domain 465 on the flood event-time scale. A sill for levels 7 and 8 (64 and 128 days) is observed, leading 466 the curve to decrease irregularly. This means that highest flood events imprint the discharge at 467 the seasonal scale. For the highest multiresolution levels, both the rainfall and discharge time 468 series become uncorrelated.

Regarding a CCF between pumping as input and drawdown as outputs ( $Q p-s$ plots in 470 Figure 7b), we observe a bimodal distribution of Rmax across levels at level 8 (128 days) and 471 level 13 (11.2 years) with $R_{\max }$ of 0.47 and 0.40 , respectively. These results show that time 472 series co-vary mainly for medium (intra-annual) and high (multi-year) levels, and that data are 473 uncorrelated in the high frequency domain.

474 Regarding a CCF between storage flows as input and residual discharge and drawdown 475 as outputs ( $Q s-Q r$ and $Q s-s$ plots in Figure 7c and 7d, respectively), we observe a similar 476 bimodal distribution of $R_{\max }$ across scales, compared to the CCF using $Q p$ as input. At level 8, 477 however, the highest correlations using $Q s$ as input $(0.39$ and 0.61 for $Q s-Q r$ and $Q s-s$ 478 respectively) showed that $Q s$ is a better signal than $Q p$ for characterizing the karst response to 479 anthropic pressure within a given year. This is especially true for $s$ as an output signal, 480 because a strong correlation is also observed for the whole spectrum of energy as evidenced 
481 by the $R_{\max }(0.84)$ of the CCF using an overall signal for input and output (dotted blue line in 482 Figure 7d).

\section{4.3 Continuous wavelet analysis}

\section{4.3.1 Wavelet power spectrum}

Multiresolution cross-correlations provide information on frequency domains which are or are not correlated between two signals, but give no information on the temporal variability

487 of their inter-relationships. The aim of this section is to investigate the short- to long-term 488 influence of climatic and anthropic pressures on the karst response using Morlet continuous wavelet analysis (CWT). Because multiresolution analysis showed that pumping rate seems to not influence the hydrogeological response in very high frequencies (several days), CWT was

491 carried out in the monthly to multi-annual frequency domain, in which anthropic impact may 492 be investigated. Figure 8 presents scalograms for all hydrogeological variables to assess the 493 spectral power variance of each hydrogeological signal at each level and at each time lag. On 494 scalograms, the $\mathrm{x}$ - and $\mathrm{y}$-axes represent the time-scale space, with frequencies expressed as 495 periods in days (high frequencies or low periods at the top of the plot). The z-axis represents 496 the value of the wavelet coefficient with low to high powers in blue to red colors. Regarding the CWT for rainfall ( $P$ in Figure $8 \mathrm{a}$ ), we identify structures in the high 498 frequency domain (less than 128 days) which are not particularly less marked in the case of 499 spring discharge ( $Q r$ in Figure 8d). This low signal attenuation in the 32 to 128-day band in $500 Q r$ highlights a high transmissive function of the infiltration zone of the karst system. 501 Generally, smallest semi-annual structures (128 to 256 days) appear concomitantly with the 502 main annual ones during wet hydrological cycles in both $P$ and $Q r$ signals (i.e. in 1976-78, 
503 1987-88, 1996-98, 2000-01, 2002-04 and 2008-09, see Figure 4). This shows the imprint of

504 rainfall fluctuations on the karst system in autumn and in a lower manner in spring season. A

505 scale-dependent structure for a 100 to 500-day period is observed in 1995 for $P$, highlighting

506 the multi-scale distribution of energy among the highest rainfall events. A 10 to 8 -year

507 component is observed from 1991 to 2003 for $P$, reflecting a clear variation in large-scale

508 rainfall distribution. This component is visible in the scalograms of $Q r$, but power is not

509 above the 5\% significance level except in the cone of influence (COI). Globally, on the

510 contrary to high and medium frequencies, these results highlight an attenuation of the lowest

511 frequencies in rainfall by the karst system. This is coherent with the multiresolution cross-

512 correlation analysis presented above, showing a poor correlation between rainfall and

513 discharge in the lowest frequencies.

$514 \quad$ Regarding CWTs for pumping, karst storage flow and groundwater level $(Q p, Q s$, and $h$

515 in Figure 8b, 8c, and 8e, respectively), we identified a high variability of periodic structures

516 over time before and after 1985. In the three scalograms, components are visible in the high

517 frequency domain (below 128 days), for a seasonal period (128-256 days) and for an annual

518 period. However, these structures, visible for $Q p$ from 1974 to 1985, disappear from 1985

519 onwards, except for some small-scale and erratic annual structures. At the same time, all these

520 structures appear for $Q s$ and $h$ in 1985 after a period without any visible component. This

521 result is consistent with the multiresolution analysis showing a gradual decrease in $Q p$ energy

522 on all scales before 1985, and a concomitant gradual increase in $Q s$ and $h$ energies after this

523 date. Again, the change in energy distribution observed since 1985 is related to the change in

524 the water resource operating strategy since the creation of deep boreholes in 1983 . On the 
525

534 precipitation as input and residual discharges as outputs ( $P-Q r$ plots in Figure 9a and 9b).

535 Except for the driest years (notably 1990-1993) coinciding with low wavelet power, 536 significant coherence between $P$ and $Q r$ appears throughout the time-scale space, suggesting 537 strong relationships between both time series at all scales. XWT highlighted an irregular 538 annual component during wet years when seasonal structures are also visible. Common 539 features from the CWT stand out as being significant on the 8 to 10 -year band from 1978 to 540 2005, showing a strong link between $P$ and $Q r$.

\section{1}

544 scalogram showed an irregular annual component during mean and dry years when the 545 surplus is not recharged, emphasizing the impact of pumping on the karst aquifer. Seasonal 546 and high frequencies are also visible irrespective of the hydrological cycle (dry or wet) 
547 showing that $Q p-s$ relationships within a given year are not dependent on the annual recharge

548 rate. No long-term influence is visible on the $Q p-s$ scalogram.

\section{4.3.2.3 Response to the cumulative effect of climatic and anthropic variations}

550 Responses to the cumulative effect of climatic and anthropic variations were 551 investigated for XWT and WTC between karst storage flow as input and residual discharges 552 and drawdown as outputs $(Q s-Q r$ plots in Figure 9e and 9f, and $Q s-s$ plots in Figure $9 \mathrm{~g}$ and 553 9h). For both the $Q s-Q r$ and $Q s$-s cross-scalograms, two main components are clearly visible 554 at 6 months and 1 year from 1985, showing a high level of co-variance between abstraction 555 from groundwater storage and residual discharge and drawdown from the implantation year of 556 the pumps directly in the karstic drain. For XWT $Q s-Q r$, the 6-month component appears 557 more irregular since it is only visible when the karst system dries rapidly during the spring 558 when the winter and spring recharge is insufficient to maintain a baseflow discharge above 559 the pumping rate $(Q s>0$ when $Q n<Q p)$. For XWT $Q s$-s, we observed significant coherence 560 throughout the time-scale space, showing strong relationships between both time series at all 561 scales. Here, it is interesting to note that no significant common features in the wavelet power 562 is visible in lowest frequencies, despite high coherence.

\section{Discussion}

564 The aim of this study was to identify using wavelet analysis the respective impacts of 565 climatic and anthropic pressures on the water resource of a karst system under active water 566 management. The first challenge was to identify the contributions of both stressors (namely 567 rainfall and pumping rate, respectively) which concomitantly influence the hydrogeological 
response. The second challenge was to track the evolution of phenomena over time and thus to identify the parameters leading to changes in the hydrogeological response of the system.

\subsection{Frequency domains in which stressors influence the karst response}

Multiresolution analysis (MRA) showed varying energy distribution across levels, meaning that the karst response was highly variable from high to low frequencies. Using multiresolution cross correlation, we determined the frequency domain where output signals (discharge and groundwater level) were most closely correlated to input signals (rainfall and pumping). Our results showed that rainfall and spring discharge are highly correlated in the high frequency domain which reflects the hydrogeological response during flood events of typical highly karstified systems. Pumping and storage flow are correlated to discharge and drawdown in the medium and low frequency domains, illustrating seasonal to multi-year relationships.

\subsection{Climatic impact}

Continuous wavelet transform (CWT) were used as a complementary approach of MRA to track tendencies and potential evolutions of the hydrogeological response. For rainfall and discharge CWTs, we showed that (i) high rainfall intensities are restored as in the discharge signal during flood events, (ii) an annual component is only visible during wet years in both signals (i.e. when extreme rain events occur), and (iii) the 10 -year rainfall component was attenuate in the discharge signal. Despite this attenuation of the lowest frequencies observed in rainfall CWT, cross-wavelet transform (XWT) and coherence (WTC) were useful to provide evidence of long-term climate impacts on spring discharge. This 10-year component 
590 should be related to rainfall oscillation in the 5 to 10-year band outlined by Pinault (2012) in

591 the western Mediterranean region. The attenuation of the large-scale rainfall component is 592 clearly different from examples of "non-managed" hydrosystems in the literature (Labat et al., 593 2000; Chinarro et al., 2011; Hao et al., 2012), which showed that in general karst systems 594 filter less high frequencies ( $<2$ months) as in our study case, but imprint highly the lowest 595 frequencies due probably to inertial processes generated by the storage volume. Likely 596 explanations of the opposite process at large-scale observed in the Lez karst system is the 597 pumping strategy within a given year that regulates the storage variations (increasing or 598 decreasing the pumping rate according to the available water resource). This interesting result 599 shows that possible long-term impacts of rainfall variability due to climate change on the 600 karst system may be masked by the high pumping rate. However, we showed that XWT and 601 WTC may be a useful approach in order to detect it. The question thus arises of whether 602 pumping can modify the hydrogeological regime of the karst system.

603

604 605 606 607 608 609 610 coherence.

611 The impact of pumping on the hydrogeological response was characterized using $Q p-s$ 612 XWTs. An irregular annual component was observed during mean and dry years on the 
613 scalogram when there is no extra-recharge. Moreover, no large-scale component was

614 highlighted, meaning that any trend exists on the hydrogeological response to pumping. In

615 fact, regulations impose a maximum drawdown in the Lez aquifer (30 m below the spring),

616 limiting the impact of pumping on storage, even after the increase of pumping rate in 1983.

617 Cross wavelet analysis and coherence showed that $Q s$ is a better signal than $Q p$ to 618 explain the piezometric levels, with $Q s$ reflecting both anthropic and climatic pressures as it 619 displays storage mobilization (i.e. pumping during periods of low groundwater levels). For 620 both $Q s-Q r$ and $Q s$-s cross-scalograms, two main components are clearly visible at 6 months 621 and 1 year from 1983. Regarding the $Q s-s$ cross-scalogram, the annual and 6-monthly 622 components appear continuous from 1983 to date, excluding irregularities in the 6-monthly 623 component during wet years. Multi-scale structures are also visible from 2 months to 1 year, 624 illustrating the scale-dependence of both series. This illustrates the anthropic and climatic 625 cumulative effects on the storage level, with continuous annual stress from the starting date of 626 active management. The absence of a large scale component between $Q s$ and $s$ (and between $627 Q s$ and $Q r$ ) can be explained by two phenomena: i) the high recharge rate during autumn in 628 Mediterranean areas, refilling the saturated zone each year, and ii) the pumping restriction 629 imposed by regulations stipulating the maximum drawdown. In this setting, the stress on the 630 groundwater resource does not increase from year to year and the present pumping strategy 631 does not affect the drawdown in the long term, avoiding an over-exploitation of the aquifer. 
6325.4 Implications on the understanding of the karst hydrogeological

633

634

635

636

637

638

639 in the conduit. In view of the continuous pumping strategy, we may assume that water stored

640 in the fissured rock matrix is highly mobilized by pumping in the conduit during low water

641 level periods. This is consistent with the results of Ladouche et al. (2014) which showed that

642 the pumping induces mobilization of water in less transmissive units. In fact, conduit/matrix

643 relationships generated by pumping have soon been observed during a 1-month pumping test

644 in the Cent-Fonts karst system (Southern France) by Maréchal et al. (2008). The authors

645 showed that both the fissured matrix (several kilometers away from the pumping well) and the

646 conduit network were affected by the test. Indeed, pumping at the Lez aquifer outlet may

647 influence the upstream part of the karst system over a long distance of about $20 \mathrm{~km}$

648 (Ladouche et al., 2014). The Matelles fault (location shown in Figure 1) is a major drainage

649 axis and the direction of groundwater flow in the Lez aquifer has been ascertained by means

650 of artificial tracer experiments (Marjolet and Salado 1975; Bérard 1983) and by interpretation

651 of monitored water levels measured along this fault (especially at the Claret well - Figure 1)

652 (Karam 1989; Conroux, 2007). 


\section{3 \\ 6 Conclusion}

654

The aim of this study was to assess the respective impact of climatic and anthropic

655 pressures on groundwater resources in a Mediterranean karst system under active water

656 management. The main interest in our study was a combination of discrete (multiresolution)

657 and continuous wavelet on 38-year hydrogeological time series recorded at the managed Lez

658 karst aquifer (South France). Our main results showed that water management modifies the

659 hydrogeological response at short and large-time scales. We assume that the reason why

660 large-scale rainfall component do not appear in the spring discharge is that groundwater

661 storage is highly affected by pumping. This result shows that possible long-term impacts of

662 rainfall variability due to climate change may be masked by a high pumping rate. Despite an

663 increase of the pumping rate from the 1980s, the stress on the groundwater resource does not

664 increase from year to year. The current regulation of the hydrogeological conditions by

665 controlling the drawdown - and thus the pumping rate - may be the reason why no long-term

666 anthropic influence was identified. This indicates that the aquifer is currently not over-

667 exploited. Thus, in case necessary, we expect that an increase of the pumping rate is again

668 possible. This study highlights the effectiveness of wavelet analysis in characterizing the

669 response variability of karst systems where the hydrogeological regime is modified by

670 pumping. In order to establish water management scenarios under climatic changes, our

671 approach may be useful to help decompose time series, extracting frequencies in which

672 climatic and anthropic components are mainly localised, before their use in modelling

673 approaches.

674 
677 BRGM. The authors wish to thank the Montpellier Agglomération, the Rhone-Mediterranean

678 and Corsica Water Agency, the Conseil Général de l'Hérault, and the Région Languedoc-

679 Roussillon for funding this work as part of the Lez-GMU project, and to thank Veolia for 680 sharing time series data.

\section{References}

683 Climatic and hydrological variations during the last 117-166 years in the south of the Iberian

684 Peninsula, from spectral and correlation analyses and continuous wavelet analyses. J. Hydrol. 685 324: 24-39.

Avias, J. (1995), Active management of Lez karstic spring, Herault, France, 1957-1994.

687 Hydrogeologie, Editions du BRGM, pp. 113-128.

688 Bakalowicz, M. ( 2005), Karst groundwater: a challenge for new resources. Hydrogeol.

689 J., 13, 148-160.

690 Banque Hydro (2010), http://www.hydro.eaufrance.fr; station No. Y3204020.

691 Bayazit, M, and H. Aksoy (2001). Using wavelets for data generation, Journal of 692 Applied Statistics, 28(2), 157-166.

693 Bérard, P. (1983), Alimentation en eau de la ville de Montpellier. Captage de la source 694 du Lez. Etude des relations entre la source et son réservoir aquifère. Rapport $n^{\circ} 2$ Definition 695 des unités hydrogeologiques, BRGM Montpellier. 
697 Geochemical evidence of water source characterization and hydrodynamic responses in a 698 karst aquifer. J. Hydrol., 450-451: 206-218.

699 Chinarro, D., J. L. Villarroel, and J. A. Cuchi (2011), Wavelet analysis of Fuenmayor 700 karst spring, San Julian de Banzo, Huesca, Spain. Environ. Earth Sci., 65:2231-2243.

701 Chui, C.K. (1992), An Introduction on Wavelets, Academic Press, San Diego, 264 p.

702 Conroux, Y. (2007), Caractérisation du fonctionnement hydrodynamique de l'aquifère 703 karstique du Lez à l'état naturel. Mémoire Master 2, Univ. Avignon 2, 151 p.

704 De Moortel, I., S.A. Munday, and A. W. Hood (2004), Wavelet analysis: The effect of 705 varying basic wavelet parameters. Solar Physic., 222:203-228.

706 Fleury, P., B. Ladouche, Y. Conroux, H. Jourde, and N. Dörfliger (2009), Modelling the 707 hydrologic functions of a karst aquifer under active water management - The Lez spring. J. 708 Hydrol., 365(3-4):235-243.

709 Fu, C., A. L. James, and M. P. Wachowiak (2012), Analyzing the combined influence 710 of solar activity and El Niño on streamflow across southern Canada, Water Resour. Res., 48, 711 W05507.

712 Goldscheider, N., D. Drew, and S. Worthington (2007), Introduction. In: Goldscheider, 713 N., Drew, D. (Eds.), Methods in Karst Hydrogeology, Taylor \& Francis, London. Int. Contrib. 714 Hydrogeol. 26, 1-8.

715 Grinsted, A., J. Moore, and S. Jevrejeva (2004), Application of the cross wavelet 716 transform and wavelet coherence to geophysical time series. Nonlinear Process. Geophys., 717 11(5-6): 561-566. 
Guilbot, A. (1975), Modélisation des écoulements d'un aquifère karstique (Liaison

719 pluie-débit). Application aux bassins de Saugras et du Lez. PhD thesis, Université des

720 Sciences et Techniques du Languedoc (Montpellier).

hydrological processes of Niangziguan Springs (North China) using wavelet analysis. Hydrol.

723 Process., 26, 3062-3069.

724

Jevrejeva, S., J. C. Moore, and A. Grinsted (2003), Influence of the Arctic Oscillation

725

726
El Niño-Southern Oscillation (ENSO) on ice conditions in the Baltic Sea: The wavelet approach, J. Geophys. Res., 108(D21), 4677, doi:10.1029/2003JD003417.

Karam, Y. (1989), Essai de modélisation des écoulements dans un aquifère karstique. Exemple de la source du Lez (Hérault, France). PhD thesis, Université Montpellier II Sciences et Techniques du Languedoc, $210 \mathrm{p}$.

Kong A Siou, L. (2011), Modélisation des crues de bassins karstiques par réseaux de neurones. Cas du bassin du Lez (France). PhD thesis, Univ. Montpellier 2, 230p.

Kumar P, Foufoula-Georgiou E. 1997. Wavelet analysis for geophysical applications. Reviews of Geophysics 35(4): 385-412.

Labat, D., R. Ababou, and A. Mangin (2000), Rainfall-runoff relations for karstic springs. Part II: continuous wavelet and discrete orthogonal multiresolution analyses, J. Hydrol., 238: 149-178.

Labat, D., R. Ababou, and A. Mangin (2001), Introduction of wavelet analyses to rainfall-runoffs relationship for karstic basins: the case of Licq-Atherey karstic system (France), Ground Water. 39(4): 605-615. 
Labat, D., R. Ababou, and A. Mangin (2002), Analyse multirésolution croisée de pluies

741 et débits de sources karstiques. C. R. Geoscience 334: 551-556.

742 Labat, D., J. Ronchailb, and J. L. Guyot (2005), Recent advances in wavelet analyses:

743 Part 2 - Amazon, Parana, Orinoco and Congo discharges time scale variability. J. Hydrol., 744 314: 289-311.

745 Labat, D. (2010), Cross wavelet analyses of annual continental freshwater discharge and 746 selected climate indices. J. Hydrol., 385: 269-278.

747 Ladouche, B, J.-C. Maréchal, and N. Dörfliger (2014). Semi-distributed lumped model 748 of a karst system under active management, J. Hydrol., 509, 215-230.

749 Lafrenière, M., and M. Sharp. (2003), Wavelet analysis of inter-annual variability in the 750 runoff regimes of glacial and nival stream catchments, Bow Lake, Alberta. Hydrol. Process. $751 \quad 17,1093-1118$.

752

Mallat, S. (2009), A wavelet tour of signal processing. The sparse Way. 3d Edition.

753 Academic Press, 805p. ISBN 13:978-0-12-374670-1

754

755

Maraun, D., and J. Kurths (2004), Cross wavelet analysis: significance testing and 756 pitfalls. Nonlinear Process. Geophys. 11, 505-514.

757

Marechal, J.C., Ladouche, B., Doerfliger, N., Lachassagne, P., 2008. Interpretation of

758 pumping tests in a mixed flow karst system. Water Resour. Res. 44, W05401, 759 doi:10.1029/2007WR006288

760 Marjolet, G. and J. Salado (1975), Contribution à l'étude de l'aquifère karstique de la 761 source du Lez (Hérault). III. Etude des écoulements d'eau dans les calcaires fissurés et 
762 karstifiés du site du futur captage de la source du Lez. Université Montpellier II. Mémoires du 763 C.E.R.G.A, Tome IX-Fac. III. 139p.

765 (2006), Investigating transport properties and turbidity dynamics of a karst aquifer using 766 correlation, spectral, and wavelet analyses. J. Hydrol., 329: 244- 257. Massei, N., A. Durand, J. Deloffre, J. P. Dupont, D. Valdes, and B. Laignel (2007), 768 Investigating possible links between the North Atlantic Oscillation and rainfall variability in 769 northwestern France over the past 35 years, J. Geophys. Res., 112, D09121, 770 doi:10.1029/2005JD007000. Mathevet, T., M. Lepiller, and A. Mangin (2004), Application of time series analyses to 772 the hydrological functioning of an Alpine karst system: the case of Bange-L'Eau-Morte. 773 Hydrology and Earth System Sciences. 8(6): 1051-1064. Météo France (2012), Rainfall data, 1974-2011. METEO France, Toulouse, France Paloc, H. (1979), Alimentation en eau de la Ville de Montpellier. Captage de la source 776 du Lez, commune de St-Clément (Hérault). Etude documentaire préalable à l'établissement 777 des périmètres de protection. Note de synthèse. Rapport BRGM 79 SGN 319 LRO, 47p.

778 Pinault, J.L., 2001. Manuel utilisateur de TEMPO, logiciel de traitement et de 779 modélisation des séries temporelles en hydrogéologie et en hydrogéochimie. BRGM, Report 780 RP-51459-FR, 221 p.

781 Pinault, J.-L, H. Pauwels, and C. Cann (2001a), Inverse modeling of the hydrological 782 and the hydrochemical behavior of hydrosystems; application to nitrate transport and 783 denitrification. Water Resour. Res. 37(8):2179-90. 

the hydrological and the hydrochemical behavior of hydrosystems; characterization of karst

786

787

788

789

790

791

792

793

794

795

796

797

798

799

800

801

802 Combined climatic and geological forcings on the spatio-temporal variability of piezometric

803 levels in the chalk aquifer of Upper Normandy (France) at pluridecennal scale. Hydrogeology

804 Journal 17: 1823-1832 system functioning. Water Resour. Res. 37(8):2191-204.

Pinault, J.-L., and D. Allier (2007), Regionalization of rainfall for broad-scale modeling: An inverse approach, Water Resour. Res., 43, W09422.

Pinault, J.-L. (2012), Global warming and rainfall oscillation in the 5-10 yr band in Western Europe and Eastern North America. Climatic Change: 114:621-650. DOI 10.1007/s10584-012-0432-6.

Salado, J. and G. Marjolet (1975), Contribution à l'étude de l'aquifère karstique de la source du Lez (Hérault). II. Etude du chimisme des eaux de la source du Lez et de son bassin. Université Montpellier 2. Mémoires du C.E.R.G.A, Tome IX-Fac. II. 101p.

Salerno, F., and G. Tartari (2009), A coupled approach of surface hydrological modelling and Wavelet Analysis for understanding the baseflow components of river discharge in karst environments. J. Hydrol., 376: 295-306.

Schaefli, B., D. Maraun, and M. Holschneider (2007), What drives high flow events in the Swiss Alps? Recent developments in wavelet spectral analysis and their application to hydrology. Advances in Water Resources 30: 2511-2525.

Slimani S, Massei N, Mesquita J, Valdés D, Fournier M, Laignel B, Dupont JP. 2009 
806 relation entre la source et son réservoir aquifère - rapport $\mathrm{n}^{\circ} 1$ : recueil des données et 807 établissement d'un modèle de cohérence. Rapport BRGM 83SGN 167 LRO

808 Thiery, D., and P. Bérard (1984), Alimentation en eau de la Ville de Montpellier 809 Captage de la source du Lez. Etude des relations entre la source et son réservoir aquifère 810 rapport $\mathrm{n}^{\circ} 3$ : modèle d'étude détaillé. Rapport BRGM 84-AGI-171-LRO/EAU

811 Torrence, C., and G.P. Compo (1998), A practical guide to wavelet analysis. Bull. Am. 812 Met. Soc. 79, 61-78.

813 Torrence, C., and P.J. Webster (1999), The annual cycle of persistence in the El Niño/ 814 Southern Oscillation. Quart. J. R. Met. Soc. 124: 1985-2004. 
816 Table 1: Guide to hydrological variables providing keys to interpret the response of the

817 hydrological system to stressors; relationships underlined in grey are used in the present

818 study.

819

\begin{tabular}{|c|c|c|c|c|}
\hline \multicolumn{2}{|c|}{ Stressors } & \multicolumn{3}{|c|}{ Karst response } \\
\hline & $\begin{array}{l}\text { Input variable } \\
\text { used to } \\
\text { characterize } \\
\text { stressors }\end{array}$ & & \multicolumn{2}{|c|}{ Output variable used to characterize the karst response } \\
\hline & & & $\begin{array}{c}\text { Qr } \\
\text { Residual discharge }\end{array}$ & $\begin{array}{c}h \text { or } s \\
\begin{array}{c}\text { Groundwater level or } \\
\text { drawdown }\end{array} \\
\end{array}$ \\
\hline $\begin{array}{l}\text { Climatic } \\
\text { pressure }\end{array}$ & $\begin{array}{c}\text { P } \\
\text { Precipitation }\end{array}$ & $\begin{array}{l}\text { Input-Output } \\
\text { relationships } \\
\text { Highlight: }\end{array}$ & $\begin{array}{c}\text { P-Qr } \\
\text { Hydrogeological response }\end{array}$ & $\begin{array}{l}\text { P-h or } \boldsymbol{P}-\mathbf{s} \\
\text { Relationship disrupted by } \\
\text { pumping }\end{array}$ \\
\hline $\begin{array}{l}\text { Anthropic } \\
\text { pressure }\end{array}$ & $\begin{array}{c}\text { Qp } \\
\text { Pumping } \\
\text { discharge }\end{array}$ & $\begin{array}{l}\text { Input-Output } \\
\text { relationships } \\
\text { Highlight: }\end{array}$ & $\begin{array}{c}\text { Qp-Qr } \\
\begin{array}{c}\text { Relationship disrupted by } \\
\text { precipitation }\end{array}\end{array}$ & Storage mobilization \\
\hline $\begin{array}{l}\text { Climatic } \\
\text { and } \\
\text { anthropic } \\
\text { pressures }\end{array}$ & $\begin{array}{c}\text { Qs } \\
\text { Karst storage } \\
\text { flow } \\
\text { mobilized by } \\
\text { pumping }\end{array}$ & $\begin{array}{l}\text { Input-Output } \\
\text { relationships }\end{array}$ & $\begin{array}{l}\text { Qs-Qr } \\
\text { Groundwater stress due to } \\
\text { active water management } \\
\text { during low groundwater level } \\
\text { periods }\end{array}$ & $\begin{array}{l}\text { Level of stress on the } \\
\text { groundwater resource }\end{array}$ \\
\hline
\end{tabular}

820

821 
822 Figure 1: Hydrogeological map of the Lez karst system.

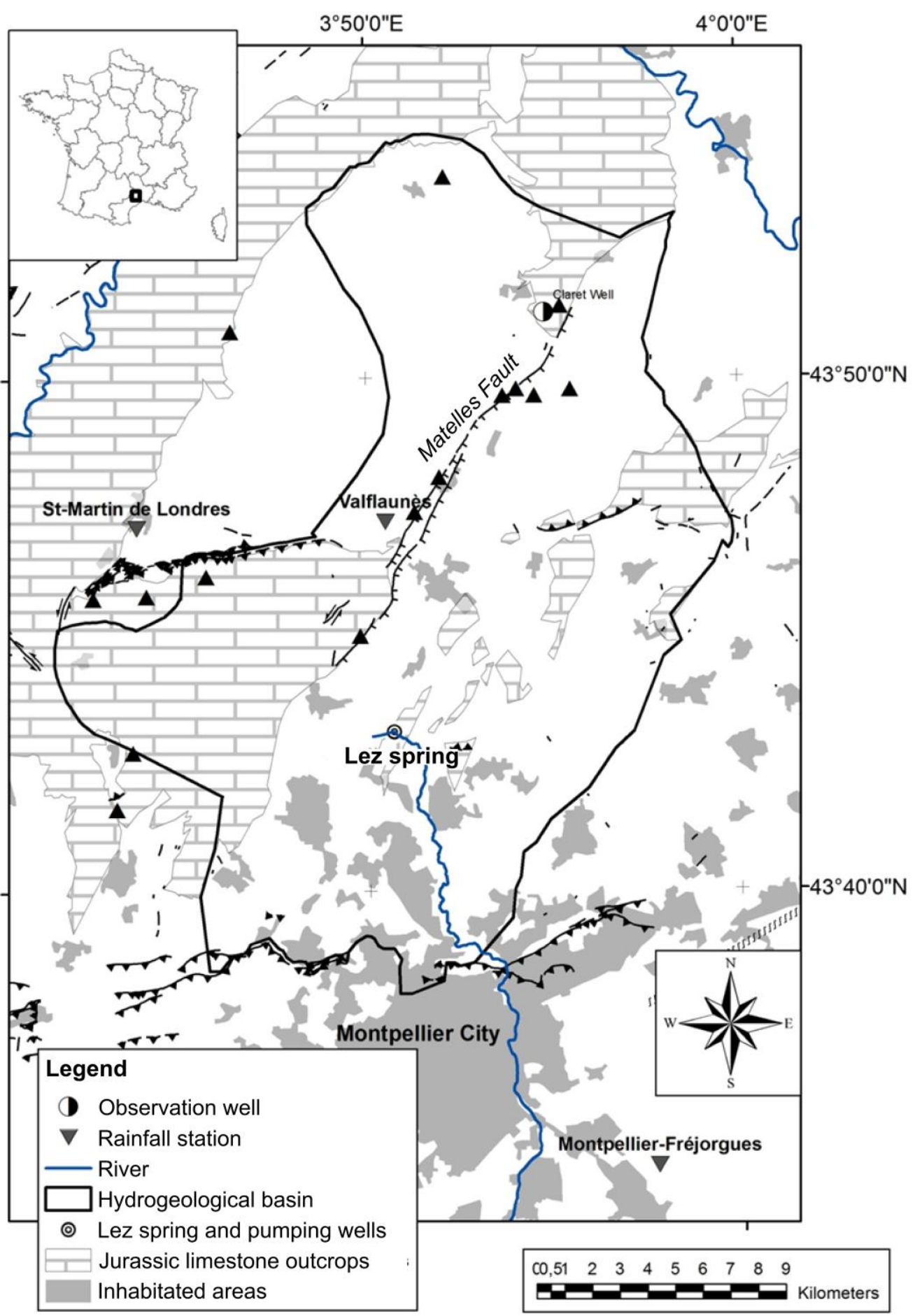

824 
825 Figure 2: Cross section of the karst network at the outlet of the Lez aquifer, showing the 826 location of the spring and of the pumping station; Piezometric levels are also plotted 827 according to high (2a) and low (2b) flow conditions.

830 Figure 3: Hydrogeological daily time series of the Lez karst system from 01 June 1974 to 31

831 December 2011 (a), and a zoom on the 2002-2003 hydrological cycle (b); from top to bottom:

832 precipitation $(P)$, measured pumping discharge $(Q p)$ and calculated storage discharge

833 mobilized by pumping ( $Q s)$, measured Lez residual discharge $(Q r)$ and simulated natural

834 discharge $(Q n)$, and the measured groundwater level in the conduit $(h)$.
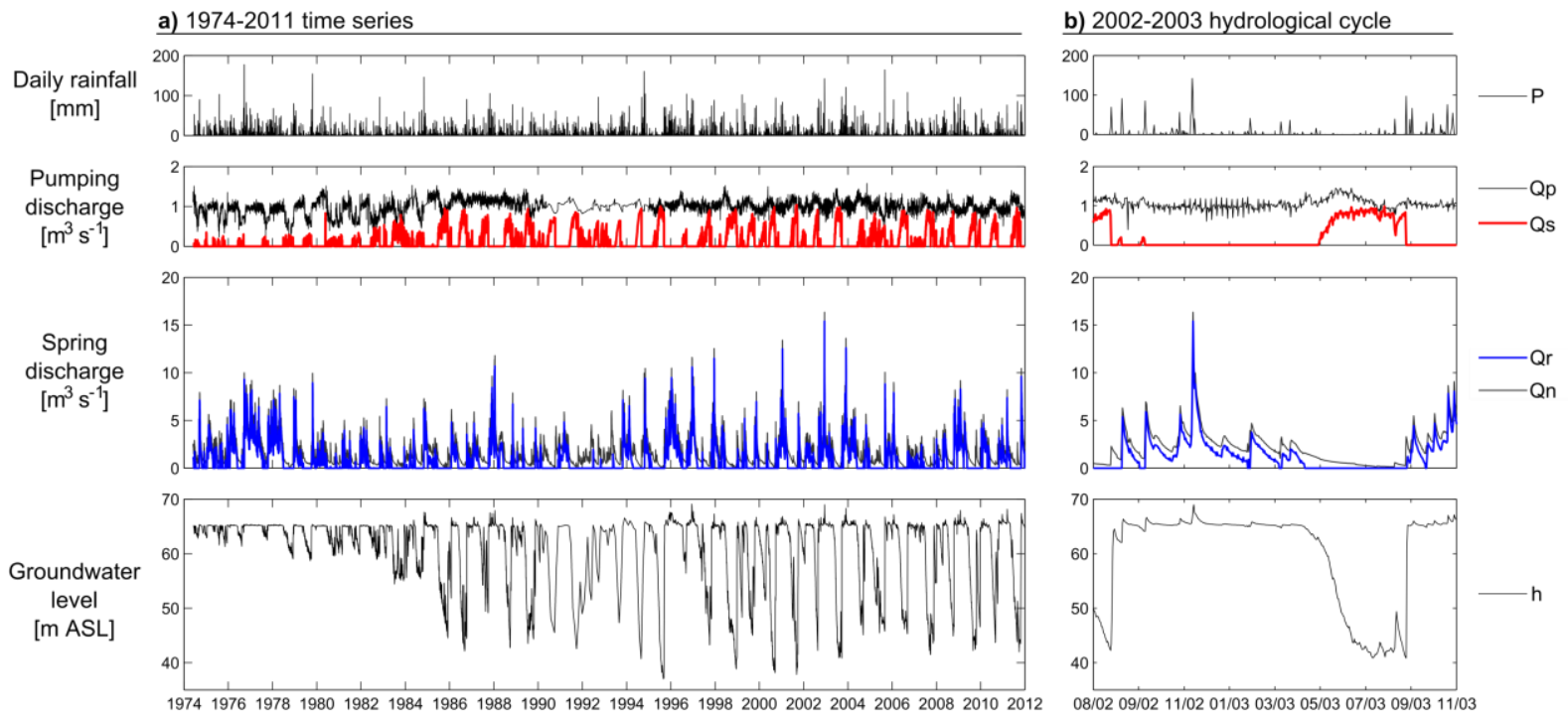

836 
837 Figure 4: Annual evolution of hydrogeological time series expressed as deviation from the

838 mean; the annual hydrological cycle was delimited from August to July.

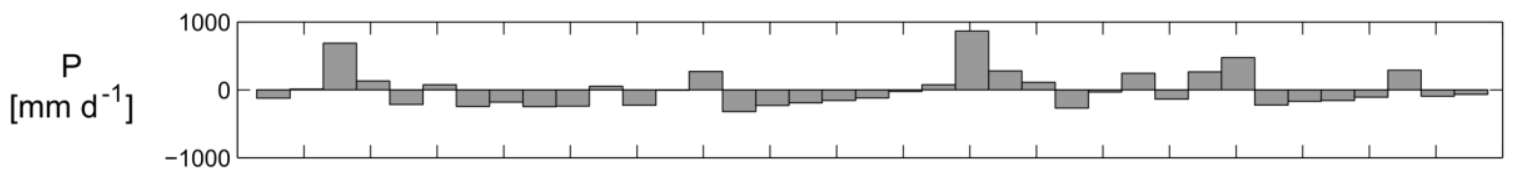

$\underset{\left[m^{3} s^{-1}\right]}{\operatorname{Qng}}$

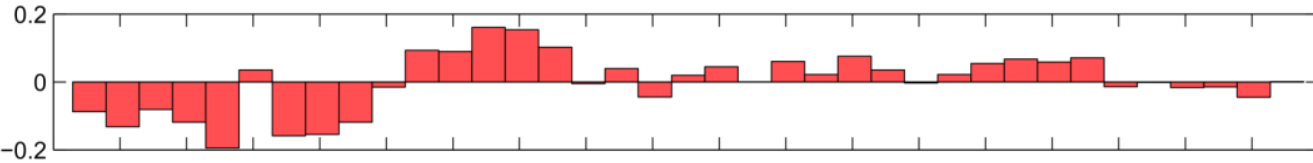

Qs

$\left[\mathrm{m}^{3} \mathrm{~s}^{-1}\right]$

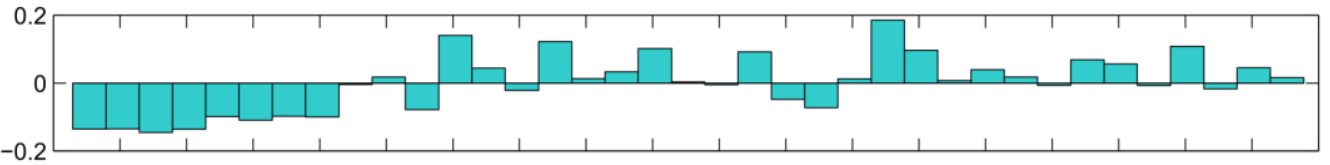

Qr

$\left[\mathrm{m}^{3} \mathrm{~s}^{-1}\right]$

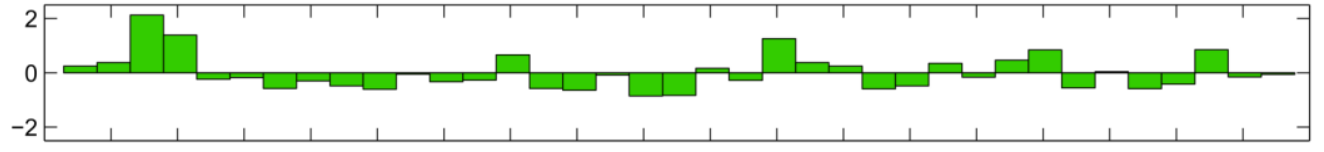

$\mathrm{h}$

[m ASL]

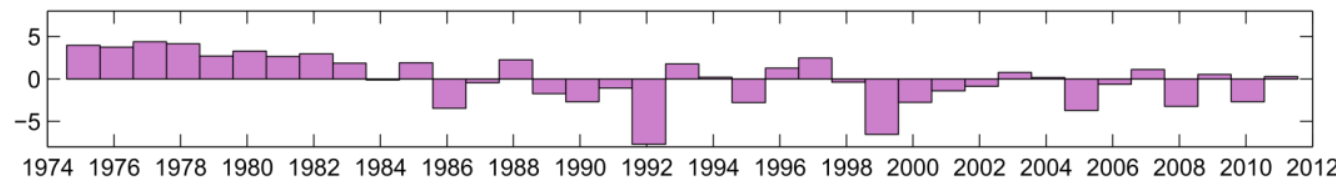

839

840 
841 Figure 5: Multiresolution analysis of daily hydrogeological time series using Daubechies 20

842 wavelets; different components of the decomposition correspond from top to bottom to short-

843 scale to long-time scale processes, with level $j$ corresponding to time scales at $2^{j-1}$; grey

844 rectangles indicate a lack of data for the first levels 1 to 3 (1 to 4-day resolution) during a

845 period of weekly raw data.

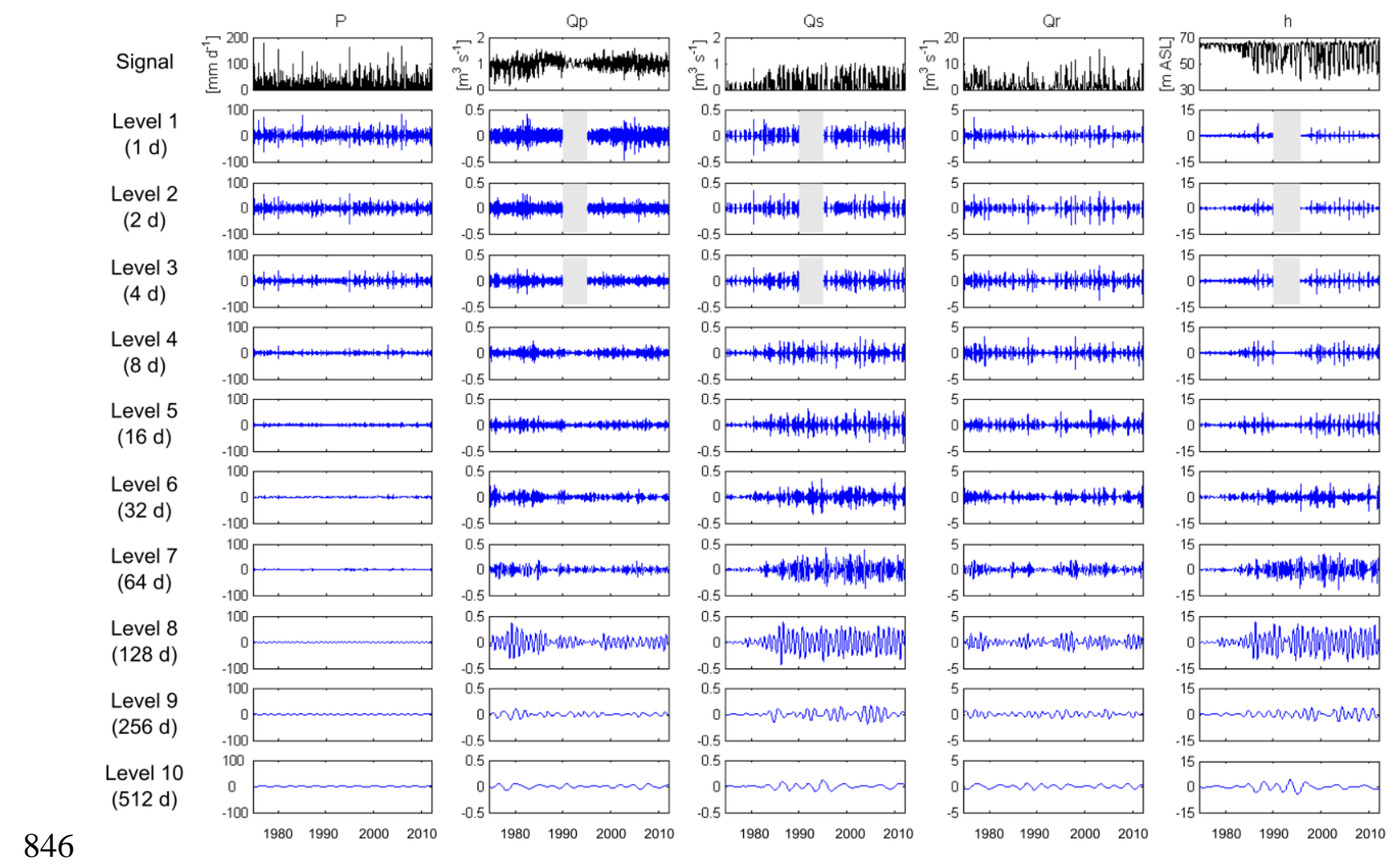


848 Figure 6: Standard deviation by multiresolution levels (from level 1 to level 14) of the 849 standardized hydrogeological signals.



850

851 
852 Figure 7: Cross-correlation functions (CCF) applied at different scales of the multiresolution 853 analysis with: $P-Q r \mathrm{CCF}$ (7a), $Q p-s \mathrm{CCF}$ (7b), $Q s-Q r \mathrm{CCF}$ (7c), and $Q s-s(7 \mathrm{~d})$; two cases are

854 shown for each plot: i) CCF between two signals at the same multiresolution level $j$ (black

855 circles), and ii) CCF between an overall input signal (i.e. a non-decomposed time series) and

856 an isolated output signal at a given multiresolution level $j$ (green stars). Maximum CCF

857 values (Rmax) are expressed as a function of the multiresolution levels in days (at level $j$, the 858 resolution corresponds to $2^{j-1}$ days). Rmax values are also plotted for CCF between two

859 overall signals (dashed blue line).
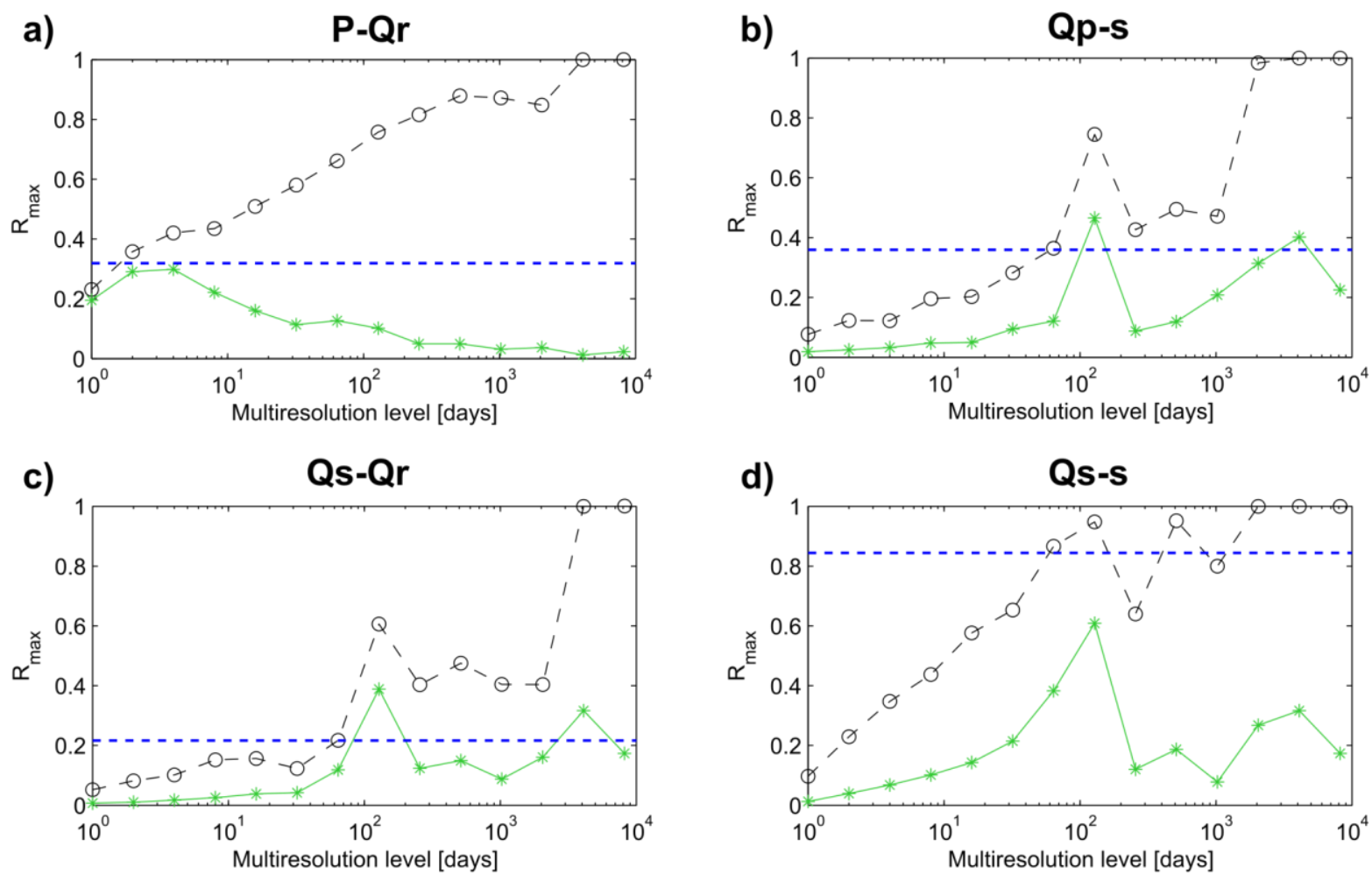

$$
\begin{aligned}
& -\ominus-\operatorname{CCF} \text { between } \mathrm{x} \text { and } \mathrm{y} \text { with } \mathrm{x}_{\mathrm{j}} \text { and } \mathrm{y}_{\mathrm{j}} \\
& -\operatorname{CCF} \text { between } \mathrm{x} \text { and } \mathrm{y} \text { with } \mathrm{x}_{\text {global }} \text { and } \mathrm{y}_{\mathrm{j}} \\
& -\ldots \text { - C CCF between } \mathrm{x} \text { and } \mathrm{y} \text { with } \mathrm{x}_{\text {global }} \text { and } \mathrm{y}_{\text {global }}
\end{aligned}
$$


862 Figure 8: Continuous wavelet power spectra of the hydrogeological time series; the thick

863 black outline designates the 5\% significance level against red noise and the cone of influence,

864 where edge effects might distort the picture, is shown in a lighter shade.
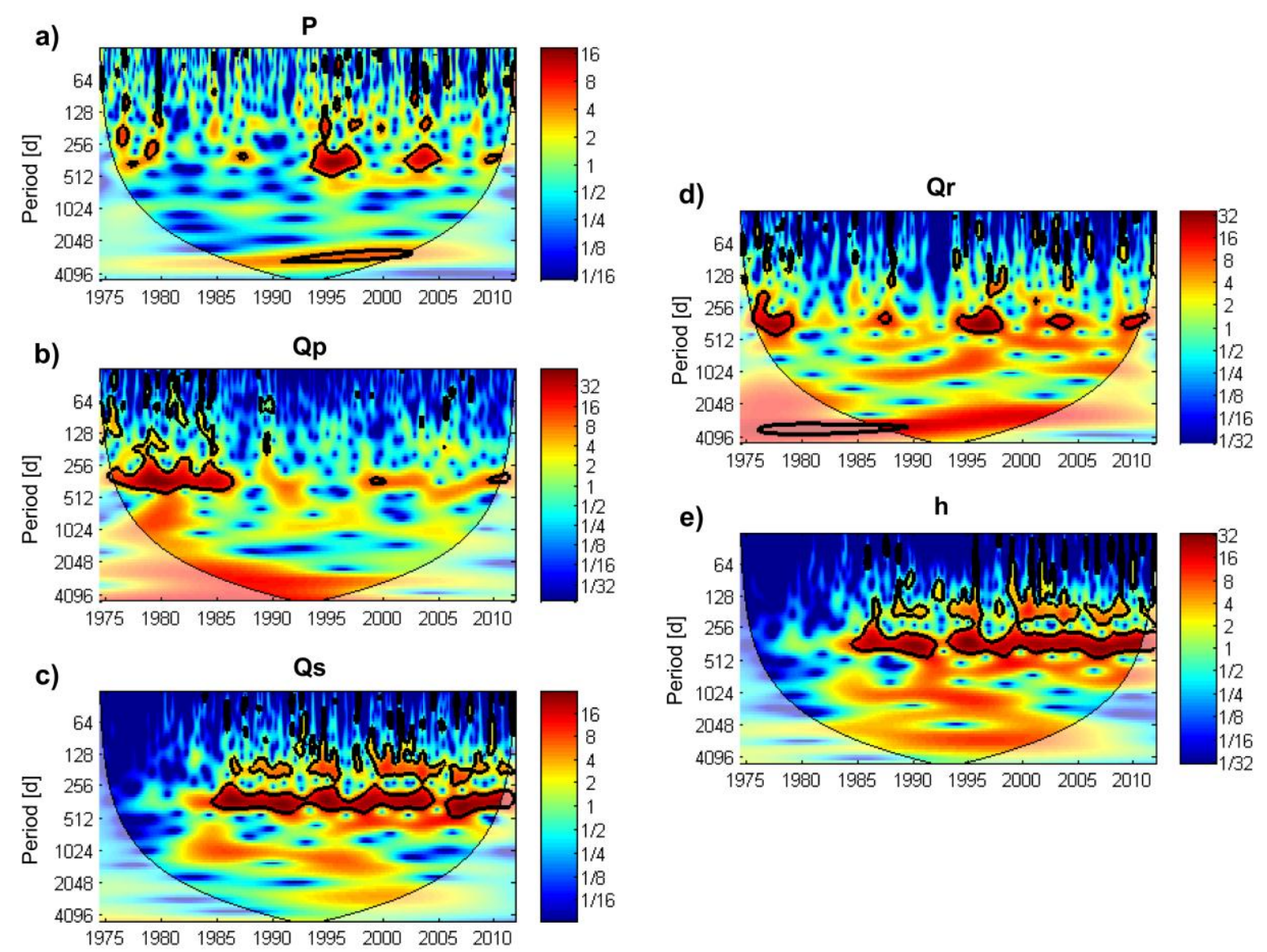
867 Figure 9: Cross wavelet (XWT) and wavelet coherence (WTC) spectra between (9a and 9b)

868 rainfall and residual Lez discharge $P-Q r,(9 \mathrm{c}$ and $9 \mathrm{~d})$ pumping and drawdown $Q p-s,(9 \mathrm{e}$ and

869 9f) groundwater stress and residual Lez discharge $Q s-Q r$, and (9g and $9 \mathrm{~h}$ ) groundwater stress

870 and drawdown $Q s-s$; The thick black outline designates the 5\% significance level against red

871 noise and the cone of influence where edge effects might distort the picture is shown as a

872 lighter shade.
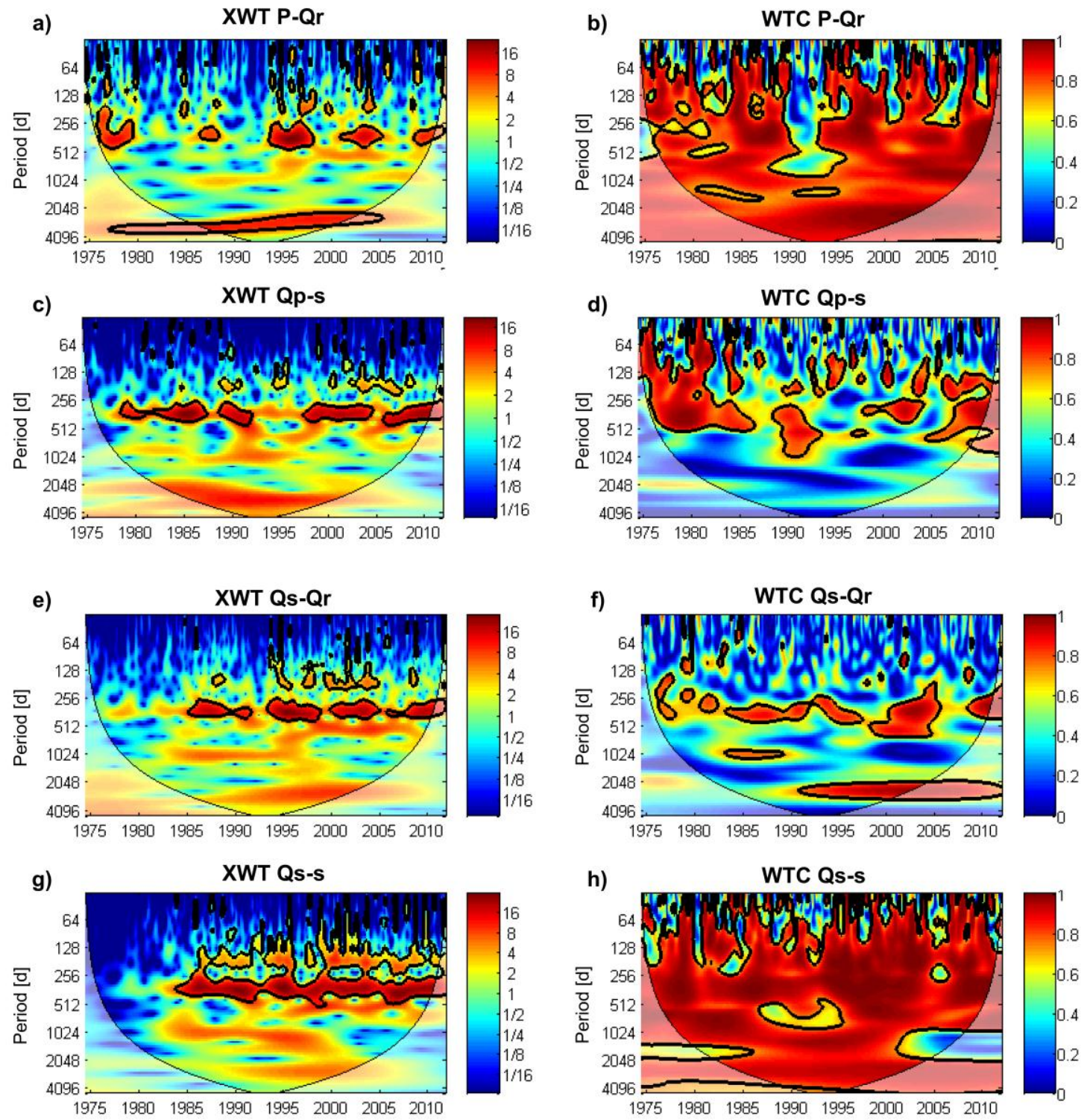